\title{
Effect of the Degree of Ionization on the Insertion of Polyvinylpyridinium Salts into Bentonite
}

\author{
Mohamed Amine Zenasni, ${ }^{1}$ Said Benfarhi, ${ }^{2}$ and Bahia Meroufel ${ }^{1}$ \\ ${ }^{1}$ Department of Sciences, Faculty of Sciences and Technology, University of Bechar, 08000 Bechar, Algeria \\ ${ }^{2}$ Department of Chemistry, Faculty of Sciences, University of Batna, 05000 Batna, Algeria
}

Correspondence should be addressed to Mohamed Amine Zenasni, am.zenasni@gmail.com

Received 1 October 2011; Accepted 5 December 2011

Academic Editor: Christopher Allen

Copyright ( 2011 Mohamed Amine Zenasni et al. This is an open access article distributed under the Creative Commons Attribution License, which permits unrestricted use, distribution, and reproduction in any medium, provided the original work is properly cited.

\begin{abstract}
The present work reports the effect of the degree of $\alpha$ ionization of poly(4-vinylpyridinium) salts (P4VPS) on the insertion of these polymer salts into bentonite. Nanocomposite materials made of a Na-montmorillonite mineral with poly(4-vinylpyridinium) salts (P4VPS) have been synthesised and characterised. The modified samples were studied by X-ray diffraction (XRD) and thermogravimetric analysis (TGA). The basic spacing of unmodified montmorillonite, determined by XRD, was measured to be $1.38 \mathrm{~nm}$; it was found to increase after modification up to $1.50 \mathrm{~nm}$. The insertion capacity of P4VPS into bentonite increased with the increasing degree of quaternisated nitrogen sites in the polymer.
\end{abstract}

\section{Introduction}

Polymer/layered silicate nanocomposites have attracted the attention of scientific researchers over the last 20 years [1].

The interaction of polymers in layered hosts, such as bentonite type montmorillonite (MMT), has proven to be a successful approach to synthesize nanophase organicinorganic hybrids. Polymer-layered silicates have been prepared by different processing techniques, such as intercalation in solution $[1,2]$, in situ polymerization $[1,3]$, and direct melt intercalation $[1,4]$. Polymerization intercalation is a method based on the use of one or more monomers that may be linearly polymerized in situ or crosslinked. This was the first method used to synthesize polymerlayered silicate nanocomposites based on polyamide $6[5$, 6]. Polymer solution intercalation is based on a solvent system in which the polymer is soluble and the silicate layers are swellable [7]. Melt intercalation is becoming attractive since it came to prominence after 1990 [8]. A number of nanocomposite materials have thus been produced by loading molten polymers with clay, predominantly layered silicates which have been organomodified [8-15].
Organoclays have recently attracted much attention in a number of applications, such as polymer-clay nanocomposites [16-18]. Organoclays are swellable smectite clays, whose surface is rendered organophilic by ionic exchange of the inorganic cations present in the clay galleries by various organic cations or polycations. Each clay particle consists of silicate layers which are about $1 \mathrm{~nm}$ thick [16-18]. Polycations are adsorbed via coulombic interactions between the cationic groups on the polymer and the negatively charged clay surface [19]. The adsorption process is essentially irreversible since desorption requires the simultaneous desorption of all the chain segments and the diffusion of the polycation away from the clay surface and into solution. Evidence for desorption of small amounts of polycation from a cleaved mica surface has been obtained by surface force measurements. Even after 5 days in a $\mathrm{K}_{2} \mathrm{SO}_{4}$ medium, very little of the polycations were found to be released [20].

Nanocomposites of montmorillonite with two poly(4vinylpyridinium) salts, the quaternized ionene polymer, and poly(4-vinylpyridine), have been synthesized and characterized. Only one macromolecular sheet of poly(4-vinylpyridinium) polyelectrolyte or of quaternized polyelectrolyte 
enters the interlayer space, irrespective of the amount of the polyelectrolyte used in the intercalation [21,22].

The object of this work was to study the effect of the degree of $\alpha$ ionization on the intercalation process. Organophilic MMT was prepared by ion exchange between $\mathrm{Na}^{+}$ions in the clay and polycationic $\left(\mathrm{P}_{4} \mathrm{VP}^{+}\right)$in aqueous medium. The nanocomposites were examined by means of X-ray diffraction (DRX) and thermogravimetric analysis (TGA).

\section{Experimental}

2.1. Materials. The bentonite used in this work comes from a quarry located in Maghnia (West of Algeria) and was supplied by company "ENOF" (an Algerian manufacture specialized in the production of nonferric products and useful substances). The different chemical elements of the native bentonite were transformed into oxides and analysed by Xray fluorescence (ENOF). Results are given in Table 1. These results confirm that the bentonite used consists essentially of montmorillonite, since the ratio $\mathrm{SiO}_{2} / \mathrm{Al}_{2} \mathrm{O}_{3}$ is equal to 3.77 and thus belongs to the family of the phyllosilicates [23]. These bentonites form stable suspensions in water and have flat platelets or needle-like structures. Granulometry of the crude bentonite has been performed in the Civil Engineering Department of Tlemcen University using a sedimentation technique with a $0.1 \%$ solution of sodium hexametaphosphate; $95 \%$ of the grains were found to have a diameter of less than $100 \mu \mathrm{m}$. The cation exchange capacity (CEC) was measured to be $80 \mathrm{meq} / 100 \mathrm{~g}$ of clay, and the surface area was $27 \mathrm{~m}^{2} / \mathrm{g}$, with an average pore size of $7 \mathrm{~nm}$.

P4VP was supplied by Aldrich. Its average molecular weight, close to $60000 \mathrm{~g}$, was determined by capillary viscosimetry, by using an empirical Mark-Houwink power law [24].

All the solvents were supplied by Aldrich (analytical grade) and used without further purification.

\subsection{Methods}

2.2.1. Preparation P4VPS/Bentonite. $2.5 \mathrm{~g}$ of bentonite was dispersed in $25 \mathrm{~mL}$ of distilled water in a $100 \mathrm{~mL}$ flask and placed under nitrogen. $0.25 \mathrm{~g}$ of P4VP was dissolved in $3.8 \mathrm{~mL}$ of methanol. To this solution $1.2 \mathrm{~mL}$ of $\mathrm{HCl}$ of various concentrations $(0.2 \mathrm{M}, 0.5 \mathrm{M}, 2 \mathrm{M}$, and $3 \mathrm{M})$, previously degassed under nitrogen, was added dropwise. The quaternisation for P4VP by various concentrations of $\mathrm{HCl}$ (different degree of $\alpha$ neutralization) therefore generated a polyelectrolyte having various load factors.

$\alpha$ is defined as the number of hydrochloric acid molecules per monomer unit,

$$
\alpha=\frac{n(\mathrm{HCl})}{n(4 \mathrm{VP})}=\frac{C(\mathrm{HCl}) \times V(\mathrm{HCl})}{n(4 \mathrm{VP})} .
$$

The mixture was stirred for $24 \mathrm{~h}$, measuring the $\mathrm{pH}$, then precipitated twice with ethyl ether, then filtered, and dried at $60^{\circ} \mathrm{C}$ for $24 \mathrm{~h}$. The solid obtained was washed 3 times with $25 \mathrm{~mL}$ of distilled water and then 3 times with $25 \mathrm{~mL}$ of methanol.
The modified bentonite samples are named P4VPS1, 2, 3, and 4/MMT (see Table 2). These samples were characterized by DRX and TGA measurements, as described below.

\subsection{Detection Method}

2.3.1. Thermogravimetric Analysis. Thermogravimetry (TG) measurements were carried out by means of a $T A$ Instruments 2950 analyzer, under air atmosphere. The same conditions were used for all the tests, with a heating rate of $10^{\circ} \mathrm{C} / \mathrm{min}$ in the temperature range of $20^{\circ} \mathrm{C}$ to $800^{\circ} \mathrm{C}$ $[25,26]$.

2.3.2. DRX Analysis. The analysis was realised by means of an automatic diffractometer Inel which has a CPS 120 detector and XRG 3000 source, using monochromatic radiation $\mathrm{K}<1$ of copper (1.54 $\AA$ ). The following operating parameters were selected: a weak speed of rotation $\left(0.01^{\circ} \mathrm{s}^{-1}\right)$ with a step of $0.01^{\circ}$ and a rather long time to obtain well-defined lines. The domain observed with the angle $2 \theta$ ranged from $2^{\circ}$ to $80^{\circ}$ for the native and cleaned bentonite and from $2^{\circ}$ to $15^{\circ}$ for the composite [27-29].

\section{Results and Discussion}

3.1. Characterization of Nanocomposite P4VPS-MMT. Different samples of nanocomposites were prepared containing various concentrations of poly(4-vinylpyridinium) salts (P4VPSs). These organobentonites were analysed by XRD and TGA.

3.1.1. X-Ray Analysis. Nanocomposite P4VPS-MMT was obtained by cationic exchange between the inorganic cations in the bentonite galleries and the polycationic surfactants P4VPS $\mathrm{N}^{+}$(poly(4-vinylpyridinium) chloride) in aqueous solution. XRD is a common technique used for examining surfactant intercalation and expansion of clay interlayer spacing after cation or polycation exchange [30-32]. As the MMT interlayer spacing expands or contracts, the $d_{001}$ reflection of XRD will shift proportionally. The $d_{001}$ spacing of clay particles was calculated according to Bragg's law

$$
d=\frac{\lambda}{2 \sin \theta} .
$$

The diffraction patterns of the pure bentonite and nanocomposite are shown in Figures 1 and 2. The X-ray patterns of pure bentonite showed a diffraction peak at $2 \theta=$ $6.39^{\circ}$, which corresponds to a layer spacing $d$ of $1.38 \mathrm{~nm}$. This value is the same as documented for Na-based montmorillonite [33]. The interlayer of the unmodified MMT contains sodium cations surrounded by one water layer in the equilibrium state [31]. The organic polycations penetrate into the interlayer space replacing the inorganic cations (in this case $\mathrm{Na}^{+}$). The synthesis of nanocomposites made of montmorillonite mineral with poly(4-vinylpyridinium) salts, quaternized ionene polymer, and poly(4-vinylpyridine) (neutral form) has been reported previously [21, 22]. 
TABLE 1: Chemical composition of the bentonite.

\begin{tabular}{|c|c|c|c|c|c|c|c|c|c|}
\hline Species & $\mathrm{SiO}_{2}$ & $\mathrm{Al}_{2} \mathrm{O}_{3}$ & $\mathrm{Fe}_{2} \mathrm{O}_{3}$ & $\mathrm{CaO}$ & $\mathrm{MgO}$ & $\mathrm{Na}_{2} \mathrm{O}$ & $\mathrm{K}_{2} \mathrm{O}$ & $\mathrm{TiO}_{2}$ & LOI \\
\hline$\%(\mathrm{w} / \mathrm{w})$ & 65.2 & 17.25 & 2.10 & 1.20 & 3.10 & 2.15 & 0.60 & 0.20 & 8.20 \\
\hline
\end{tabular}

TABLE 2: Used quantities.

\begin{tabular}{lcccccc}
\hline Sample & $\mathrm{P}_{\mathrm{VP}}(\mathrm{mg})$ & $\mathrm{BC}(\mathrm{mg})$ & $\mathrm{C}_{\mathrm{HCl}}(\mathrm{mole} / \mathrm{l})$ & $\alpha$ & $\mathrm{pH}$ & Rate of conversion $(\%)$ \\
\hline P4VPS1/MMT & 250 & 2500 & 0.2 & 0.1 & 3.8 & 60 \\
P4VPS2/MMT & 250 & 2500 & 0.5 & 0.25 & 2.5 & 60 \\
P4VPS3/MMT & 250 & 2500 & 3 & 1 & 1.2 & 67 \\
P4VPS4/MMT & 250 & 2500 & & 1.5 & 0.5 & 66 \\
\hline
\end{tabular}

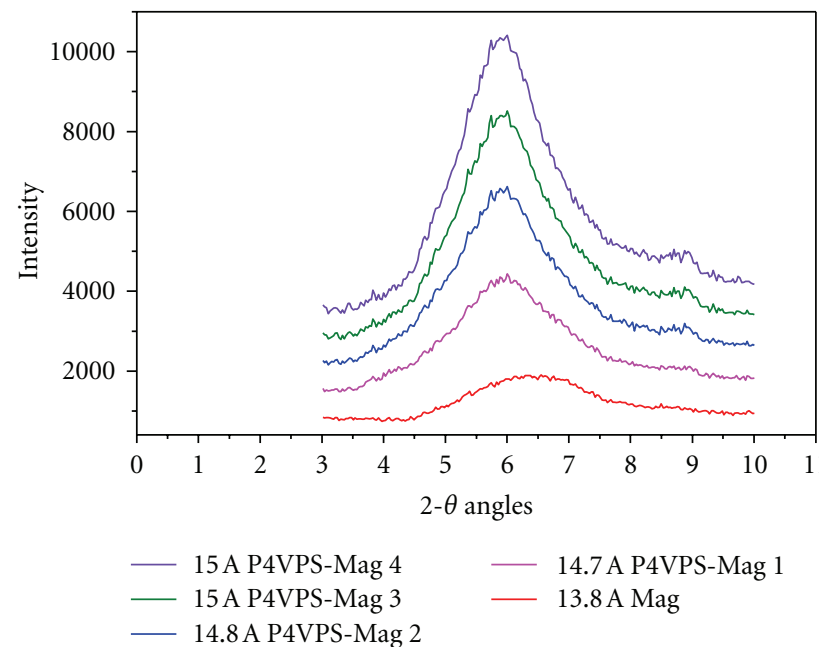

Figure 1: X-ray diffraction patterns of curves: Maghnite and P4VPS-Maghnite.

Figure 1 shows the XRD patterns of organobentonites containing different concentrations of P4VPS polymer salts, and therefore different degrees of $\alpha$ ionization, which were obtained by solution intercalation.

The primary silicate reflection at $2 \theta=5.98^{\circ}$ in the nanocomposites with a degree of ionization $\alpha=0.1$ corresponds to a layer spacing of $1.47 \mathrm{~nm}$, which represents an increase of approximately $0.1 \mathrm{~nm}$. The organophilic treatment not only causes a change in the position of the peak maximum, providing information about the periodicity in the arrangement of the basaltic planes, but it also affects the shape of this maximum (intensity and width) which is directly related to the degree of regularity of the macrolattice. For organobentonite, a sharper peak is observed, which indicates the formation of a more regular structure through this modification [34].

For the P4VPS-MMT nanocomposites obtained via solution intercalation, the gallery spacing was found to increase slightly with the degree of $\alpha$ ionization. The (001) peak of the P4VPS-MMT sample having a degree of ionization $\alpha=$ 0.25 corresponds to a $\mathrm{d}$ value of $1.47 \mathrm{~nm}\left(2 \theta=5.98^{\circ}\right)$, while for the P4VPS-MMT having a higher degree of ionization $\alpha=1.5$, the $d$ value was found to reach $1.5 \mathrm{~nm}\left(2 \theta=6.39^{\circ}\right)$. This trend was attributed to the greater concentration of

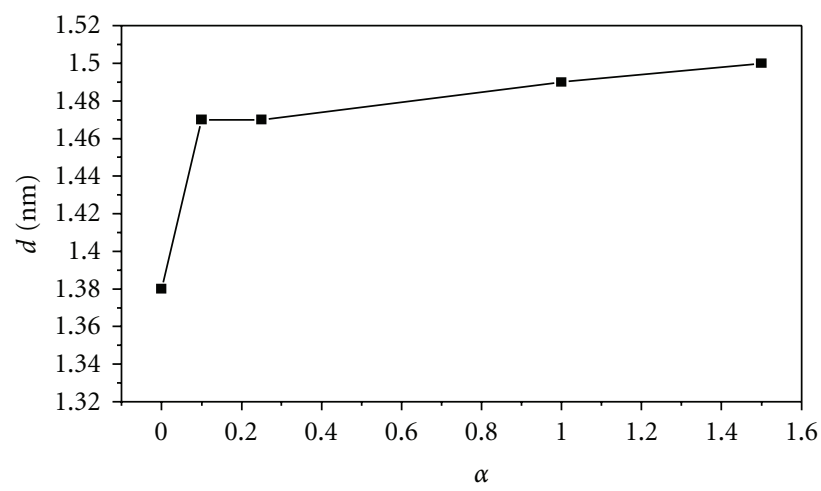

FIGURE 2: Layer spacing $d_{001}$ as a function of the degree of ionization $\alpha$.

TABLE 3: Effect of the degree of ionization $\alpha$ on the percentage of P4VPS introduces into bentonite on the interlamellar space.

\begin{tabular}{lcccc}
\hline Sample & $\alpha$ & $\begin{array}{c}\text { Polymeric salt } \\
\text { content }(\%)\end{array}$ & $d(\mathrm{~nm})$ & $2 \theta\left(^{\circ}\right)$ \\
\hline Bentonite & 0 & - & 1.38 & 6.39 \\
P4VP/MMT [37] & 0 & 7.2 & - & - \\
P4VPS1/MMT & 0.1 & 8.6 & 1.47 & 5.98 \\
P4VPS2/MMT & 0.25 & 9.5 & 1.47 & 5.98 \\
P4VPS3/MMT & 1 & 9.6 & 1.49 & 5.90 \\
P4VPS4/MMT & 1.5 & 7.1 & 1.50 & 5.88 \\
\hline
\end{tabular}

$\mathrm{HCl}$ which leads to a more extensive quaternization of the polymer, thus facilitating the penetration of P4VPS into the clay galleries (Figure 2).

3.1.2. Thermogravimetric Analysis. The course of the thermal degradation of these clay-based materials can be closely followed by means of thermogravimetric analysis (TGA). There are three important parameters which characterise the thermal stability of a given material: the onset temperature of the degradation (defined as the temperature at which $10 \%$ of the sample is lost), the midpoint of the degradation $(50 \%$ loss), and the fraction of material that is nonvolatile at $600^{\circ} \mathrm{C}$, known as char $[35,36]$.

Table 3 and Figures 3 and 4 show the TGA data and the curves from which the data were extracted. For the unmodified bentonite, an initial weight loss between $30^{\circ} \mathrm{C}$ 


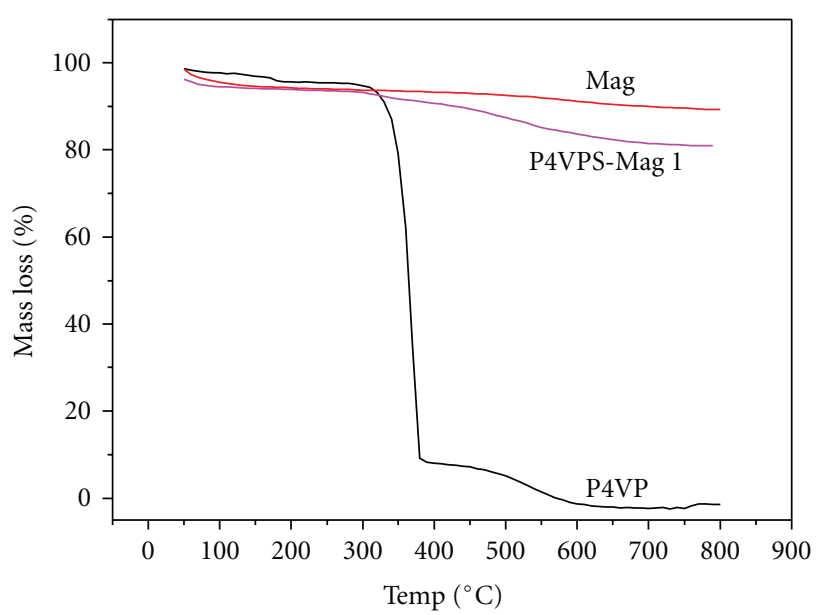

(a)

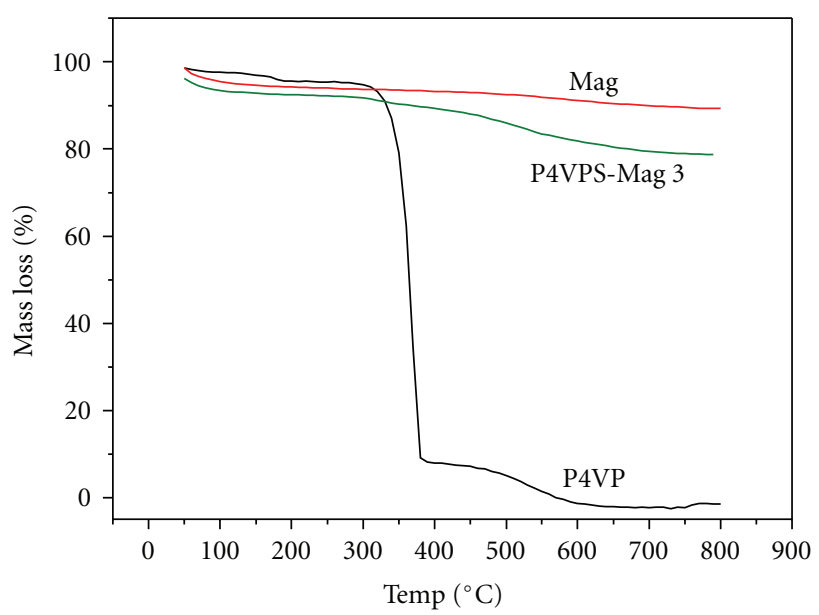

(c)

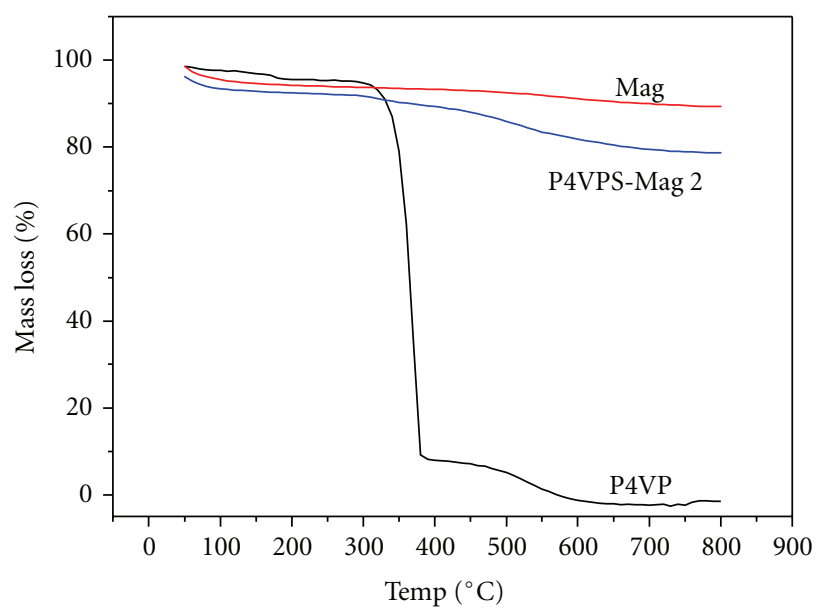

(b)

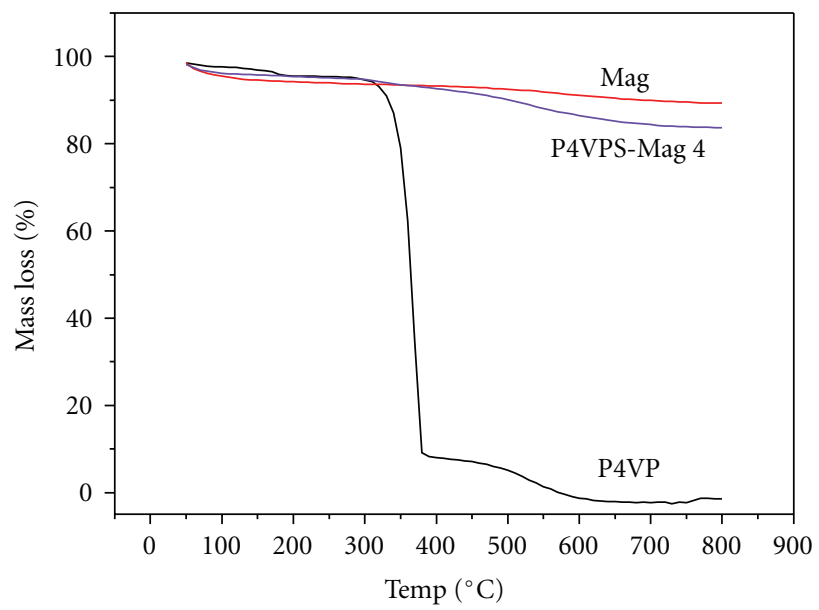

(d)

Figure 3: TGA curves for P4VP, Mag, and P4VPS-Maghnite.

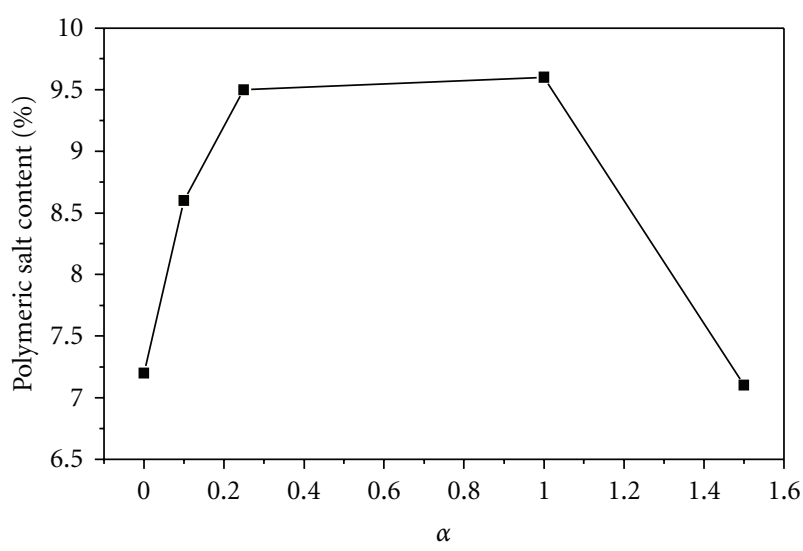

FIGURE 4: Polymeric salt content versus the degree of ionization $\alpha$.

and $200^{\circ} \mathrm{C}$ is observed due to the residual water in the sample. The weight loss observed between $430^{\circ} \mathrm{C}$ and $634^{\circ} \mathrm{C}$ was attributed to the dehydroxylation of the aluminosilicate $[38,39]$.

For the P4VPS-MMT-modified clay, the more important weight loss observed was attributed to the polymer salt decomposition between $230^{\circ} \mathrm{C}$ and $800^{\circ} \mathrm{C}$. This type of behaviour has been previously observed by Xie et al. [40], who suggested that montmorillonite acts as a catalyst for the degradation of such organic salts, with a reduction of up to $25^{\circ} \mathrm{C}$ in their decomposition temperature. They considered that, in the organoclay, the basic nature of the surface of the aluminosilicate promotes a nucleophilic SN2 reaction or a Hoffman reaction, with formation of alkanes, alkenes, and tertiary amines. This decomposition occurs when the polymer molecules are located either at the outside or in the interlamellar region, at temperatures below the decomposition temperature of the pure quaternary polymers salt (P4VPS). The high-molecular-weight molecules resulting from the polymer salt decomposition are assumed to be retained within the interlamellar region [39]. The actual content of polymeric salt incorporated into the bentonite was evaluated from the difference between the total weight losses 
observed in the range of 230 to $800^{\circ} \mathrm{C}$ for unmodified clay and organoclay.

The amount of polymer salt (P4VPS) inserted into the bentonite structure depends on the degree of $\alpha$ ionization. It was found to increase from $7.2 \%$ for neutral P4VP $(\alpha=$ 0 ) [37] to $8.6 \%$ for P4VPS $(\alpha=0.1)$. This amount rose to a maximum value of $9.6 \%$ which is close to the total quantity of P4VPS used $(10 \mathrm{w} \%)$. It decreased on further increase of the degree of ionization, down to a value of $7.1 \%$ for $\alpha=1.5$. This decrease was attributed to some reaction of the polymer salt with the increasing amount of $\mathrm{HCl}$. By creating positive charges on the nitrogen atom of the polymer, it causes an increase in the average dimension of polymer chains, due to the repulsion from internal electrostatics. These results thus clearly show the importance of the degree of ionization on the incorporation of P4VPS into bentonite and the resulting exfoliation of this clay.

\section{Conclusion}

The insertion of a polycationic surfactant, poly(4-vinylpyridinium) salt (P4VPS) into Algeria bentonite clay particles (Bentonite) was studied. The objectives were to determine the effects of the degree of ionization $\alpha$ of P4VPS on the adsorption capacity of bentonite.

By means of XRD analysis, it was shown how the interlayer spacing in bentonite increases upon insertion of P4VPS. The presence of poly(4-vinylpyridinium) chloride in the interlamellar space (intercalated nanocomposite) has been confirmed by thermogravimetric analysis (TGA).

The results obtained indicate the interest of considering the degree of $\alpha$ ionization and the structure of the polycationic surfactants to predict the capacity of a given bentonite to adsorb these compounds. The high affinity between P4VPS and bentonite was attributed to electrostatic interactions between the clay particles in ambient basic suspensions and the positively charged polycationic surfactant.

The results reported herein should help in selecting the appropriate conditions for achieving an effective exfoliation of the clay particles by treatment with P4VP and quaternary ammoniums salts. The incorporation of organomodified bentonite will affect the crystallisation by generating nucleating sites, especially in the case of bentonite combined to a primary ammonium surfactant.

\section{References}

[1] S. R. Suprakas and M. Okamoto, "Polymer/layered silicate nanocomposites: a review from preparation to processing," Progress in Polymer Science, vol. 28, no. 11, pp. 1539-1641, 2003.

[2] Q. Li, Q.-Y. Yue, Y. Su, B.-Y. Gao, and L. Fu, "Cationic polyelectrolyte/bentonite prepared by ultrasonic technique and its use as adsorbent for Reactive Blue K-GL dye," Journal of Hazardous Materials, vol. 147, no. 1-2, pp. 370-380, 2007.

[3] M. Saric, H. Dietsch, and P. Schurtenberger, "In situ polymerisation as a route towards transparent nanocomposites: timeresolved light and neutron scattering experiments," Colloids and Surfaces A, vol. 291, no. 1-3, pp. 110-116, 2006.
[4] N. N. Bhiwankar and R. A. Weiss, "Melt intercalation/exfoliation of polystyrene-sodium-montmorillonite nanocomposites using sulfonated polystyrene ionomer compatibilizers," Polymer, vol. 47, no. 19, pp. 6684-6691, 2006.

[5] Y. Fukushima, A. Okada, M. Kawasumi, and O. Kamigaito, "Swelling behaviour of montmorillonite by poly-6-amide," Clay Minerals, vol. 23, pp. 27-34, 1988.

[6] A. Okada, M. Kawasumi, A. Usuki, Y. Kojima, T. Kurauchi, and O. Kamigaito, "Nylon 6-clay hybrid," Materials Research Society Proceedings, vol. 171, pp. 45-50, 1990.

[7] D. J. Greenland, "Adsorption of polyvinyl alcohols by montmorillonite," Journal of Colloid Science, vol. 18, no. 7, pp. 647664, 1963.

[8] R. A. Vaia, H. Ishii, and E. P. Giannelis, "Synthesis and properties of two-dimensional nanostructures by direct intercalation of polymer melts in layered silicates," Chemistry of Materials, vol. 5, no. 12, pp. 1694-1696, 1993.

[9] R. A. Vaia, S. Vasudevan, W. Krawiec, L. G. Scanlon, and E. P. Giannelis, "New polymer electrolyte nanocomposites: melt intercalation of poly(ethylene oxide) in mica-type silicates," Advanced Materials, vol. 7, no. 2, pp. 154-156, 1995.

[10] W. Krawiec, L. G. Scanlon, J. P. Fellner, R. A. Vaia, S. Vasudevan, and E. P. Giannelis, "Polymer nanocomposites: a new strategy for synthesizing solid electrolytes for rechargeable lithium batteries," Journal of Power Sources, vol. 54, no. 2, pp. 310-315, 1995.

[11] R. A. Vaia, K. D. Jandt, E. J. Kramer, and E. P. Giannelis, "Kinetics of polymer melt intercalation," Macromolecules, vol. 28, no. 24, pp. 8080-8085, 1995.

[12] M. Sikka, L. N. Cerini, S. S. Ghosh, and K. I. Winey, "Melt intercalation of polystyrene in layered silicates," Journal of Polymer Science, Part B, vol. 34, no. 8, pp. 1443-1449, 1996.

[13] M. Laus, O. Francescangeli, and F. Sandrolini, "New hybrid nanocomposites based on an organophilic clay and poly(styrene-b-butadiene) copolymers," Journal of Materials Research, vol. 12, no. 11, pp. 3134-3139, 1997.

[14] L. Liu, Z. Qi, and X. Zhu, "Studies on nylon 6/Clay nanocomposites by melt-intercalation process," Journal of Applied Polymer Science, vol. 71, no. 7, pp. 1133-1138, 1999.

[15] B. Liao, M. Song, H. Liang, and Y. Pang, "Polymer-layered silicate nanocomposites. 1. A study of poly(ethylene oxide)/ $\mathrm{Na}^{+}$-montmorillonite nanocomposites as polyelectrolytes and polyethylene-block-poly(ethylene glycol) copolymer/ $\mathrm{Na}^{+}$montmorillonite nanocomposites as fillers for reinforcement of polyethylene," Polymer, vol. 42, no. 25, pp. 10007-10011, 2001.

[16] S. Qutubuddin and X. Fu, "Polymer-clay nanocomposites: synthesis and properties," in Nano-Surface Chemistry, M. Rosoff, Ed., pp. 653-673, Marcel Dekker, New York, NY, USA, 2002.

[17] A. Giannakas, C. G. Spanos, N. Kourkoumelis, T. Vaimakis, and A. Ladavos, "Preparation, characterization and water barrier properties of PS/organo-montmorillonite nanocomposites," European Polymer Journal, vol. 44, no. 12, pp. 39153921, 2008.

[18] E. P. Giannelis, "Polymer layered silicate nanocomposites," Advanced Materials, vol. 8, no. 1, pp. 29-35, 1996.

[19] C. Breen, "The characterisation and use of polycationexchanged bentonites," Applied Clay Science, vol. 15, no. 1-2, pp. 187-219, 1999.

[20] P. M. Claesson, M. A. G. Dahlgren, and L. Eriksson, "Forces between polyelectrolyte-coated surfaces: relations between surface interaction and floc properties," Colloids and Surfaces A, vol. 93, no. C, pp. 293-303, 1994. 
[21] K. G. Fournaris, M. A. Karakassides, D. Petridis, and K. Yiannakopoulou, "Clay-polyvinylpyridine nanocomposites," Chemistry of Materials, vol. 11, no. 9, pp. 2372-2381, 1999.

[22] K. G. Fournaris, N. Boukos, and D. Petridis, "Aqueous polymerization of protonated 4-vinylpyridine in montmorillonite," Applied Clay Science, vol. 19, no. 1-6, pp. 77-88, 2001.

[23] J. Mering, "Smectites," in Encyclopedia of Soil Science, pp. 97119, 1975.

[24] E. Choukchou-Braham, I. Benabadji, A. Mansri, and J. François, "Molecular weight influence on viscosimetric parameters of poly(4-vinylpyridine) polymers," European Polymer Journal, vol. 39, no. 2, pp. 297-303, 2003.

[25] R. Barbosa, E. M. Araújo, A. D. de Oliveira, and T. J. A. de Melo, "Effect of quaternary ammonium salts on the organophilization of national bentonite clay," Cerâmica, vol. 52, pp. 264-268, 2006.

[26] M. Modesti, S. Besco, A. Lorenzetti et al., "ABS/clay nanocomposites obtained by a solution technique: influence of clay organic modifiers," Polymer Degradation and Stability, vol. 92, no. 12 , pp. 2206-2213, 2007.

[27] O. Muserref and C. Meltem, "Polymethacrylamide/Namontmorillonite nanocomposites synthesized by free-radical polymerization," Materials Letters, vol. 60, pp. 48-52, 2006.

[28] J. Xiong, Y. Liu, X. Yang, and X. Wang, "Thermal and mechanical properties of polyurethane/montmorillonite nanocomposites based on a novel reactive modifier," Polymer Degradation and Stability, vol. 86, pp. 549-555, 2004.

[29] Z. Shen, G. P. Simon, and Y. B. Cheng, "Saturation ratio of poly(ethylene oxide) to silicate in melt intercalated nanocomposites," European Polymer Journal, vol. 39, no. 9, pp. 19171924, 2003.

[30] B. Zhang, Y. Li, X. Pan, X. Jia, and X. Wang, "Intercalation of acrylic acid and sodium acrylate into kaolinite and their in situ polymerization," Journal of Physics and Chemistry of Solids, vol. 68, no. 2, pp. 135-142, 2007.

[31] S. Pavlidou and C. D. Papaspyrides, "A review on polymerlayered silicate nanocomposites," Progress in Polymer Science, vol. 33, no. 12, pp. 1119-1198, 2008.

[32] B. Witthuhn, T. Pernyeszi, P. Klauth, H. Vereecken, and E. Klumpp, "Sorption study of 2,4-dichlorophenol on organoclays constructed for soil bioremediation," Colloids and Surfaces A, vol. 265, pp. 81-87, 2005.

[33] W. W. Emerson, “Organo-clay complexes," Nature, vol. 180, no. 4575 , pp. $48-49,1957$.

[34] M. V. Burmistr, K. M. Sukhyy, V. V. Shilov et al., "Synthesis, structure, thermal and mechanical properties of nanocomposites based on linear polymers and layered silicates modified by polymeric quaternary ammonium salts (ionenes)," Polymer, vol. 46, no. 26, pp. 12226-12232, 2005.

[35] A. I. Balabanovich, W. Schnabel, G. F. Levchik, S. V. Levchik, and C. A. Wilkie, "Fire retardancy of polymers," Royal Society of Chemistry, pp. 236-251, Cambridge, UK, 1998.

[36] C. Grace, W. Dongyan, and A. Charles, "Polystyrene nanocomposites based on quinolinium and pyridinium surfactants," Polymer Degradation and Stability, vol. 91, no. 4, pp. 848-855, 2006.

[37] M. Bacquet, B. Martel, M. Morcellet et al., "Adsorption of poly(4-vinylpyridine) onto bentonites," Materials Letters, vol. 58, no. 3-4, pp. 455-459, 2004.

[38] C. O. Rohlmann, M. F. Horst, L. M. Quinzani, and M. D. Failla, "Comparative analysis of nanocomposites based on polypropylene and different montmorillonites," European Polymer Journal, vol. 44, no. 9, pp. 2749-2760, 2008.
[39] F. G. Ramos Filho, T. J. A. Mélo, M. S. Rabello, and S. M. L. Silva, "Thermal stability of nanocomposites based on polypropylene and bentonite," Polymer Degradation and Stability, vol. 89, no. 3, pp. 383-392, 2005.

[40] W. Xie, Z. Gao, W. P. Pan, D. Hunter, A. Singh, and R. Vaia, "Thermal degradation chemistry of alkyl quaternary ammonium Montmorillonite," Chemistry of Materials, vol. 13, no. 9, pp. 2979-2990, 2001. 


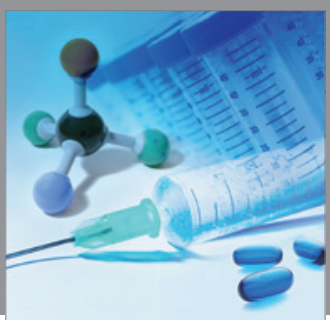

International Journal of

Medicinal Chemistry

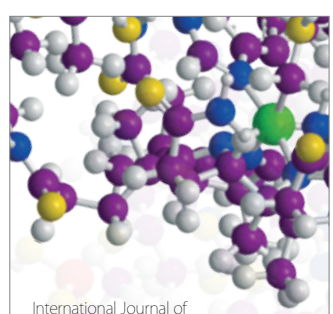

Carbohydrate Chemistry

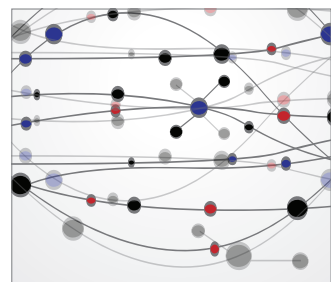

The Scientific World Journal
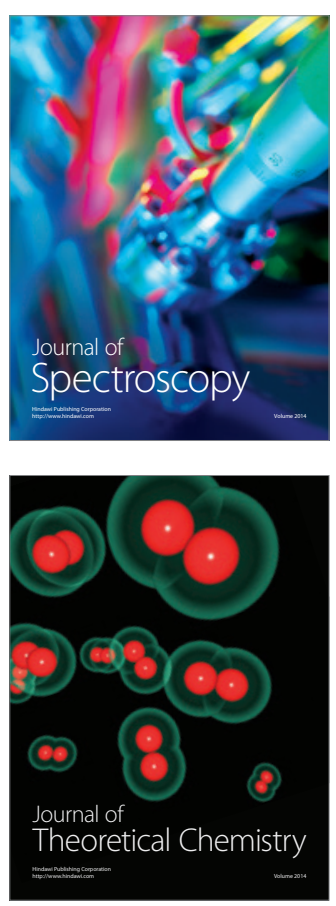
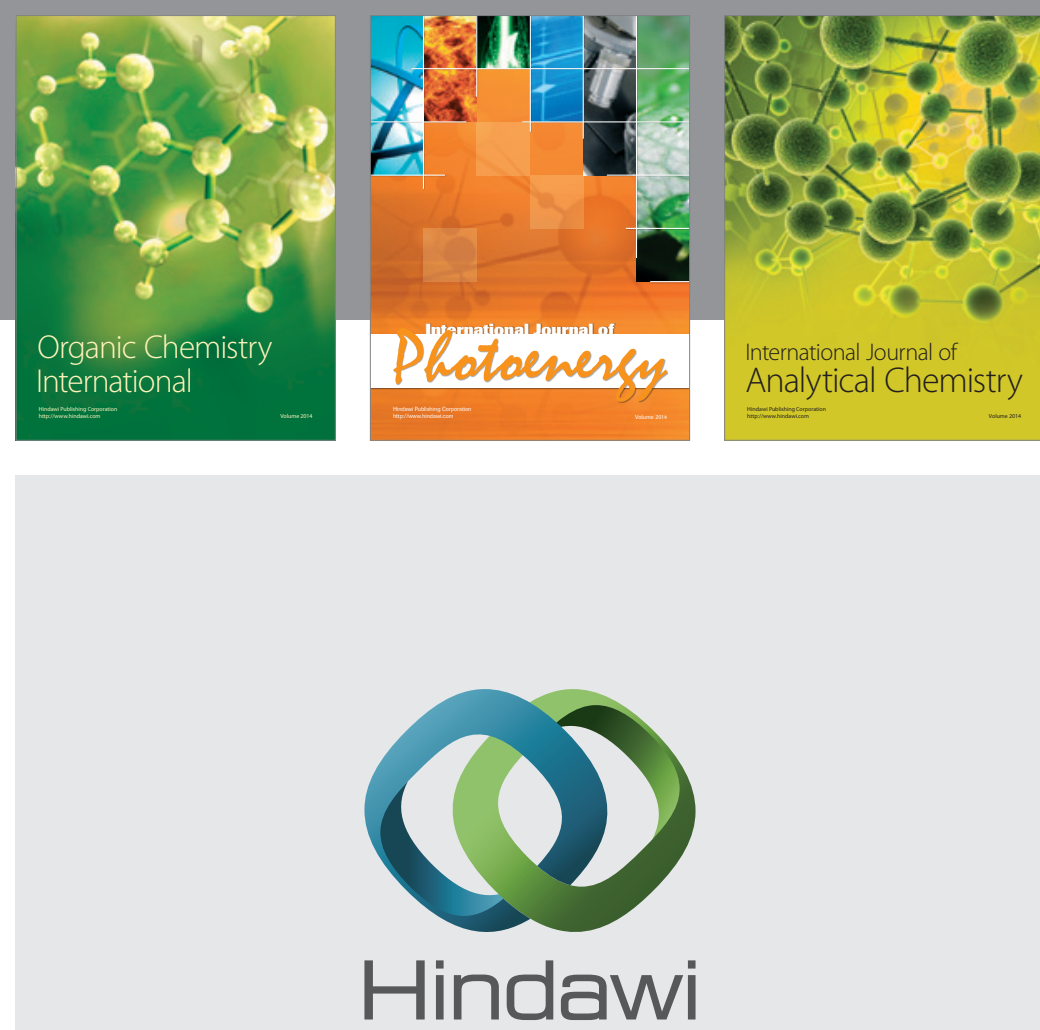

Submit your manuscripts at

http://www.hindawi.com
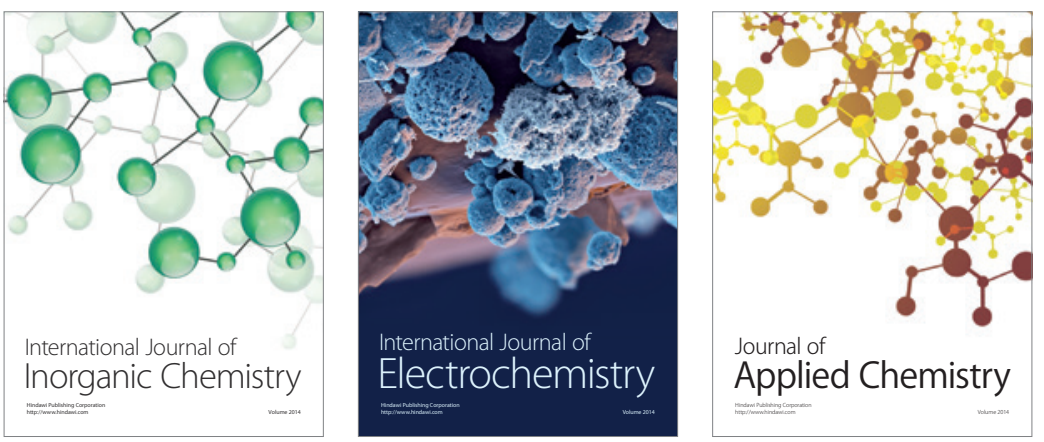

Journal of

Applied Chemistry
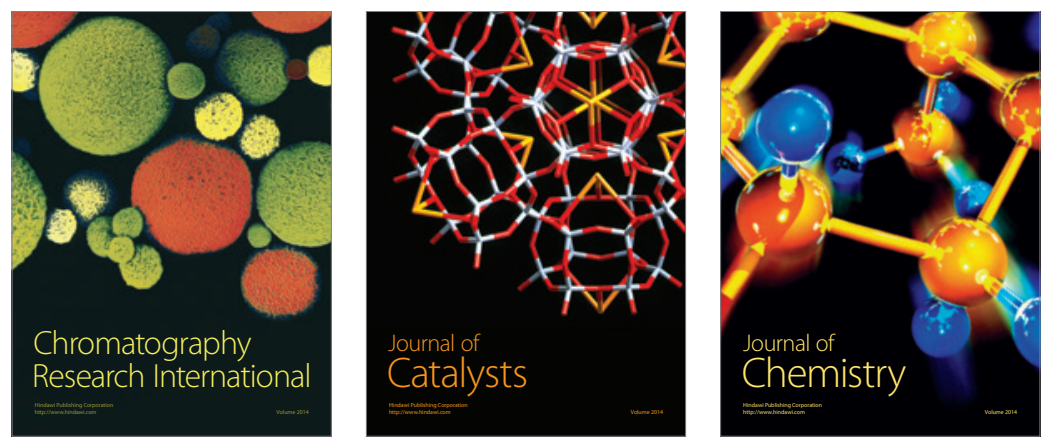
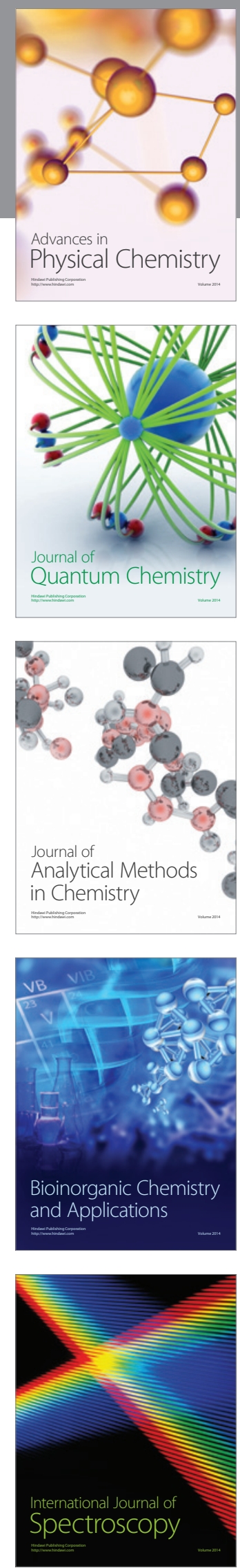